\title{
The teaching of medical ethics from a junior doctor's viewpoint
}

\author{
Susan A T Law Royal Air Force Medical Services
}

\section{Author's abstract}

This is a short paper covering my own views on the methods and reasons behind the teaching of medical ethics. All the whys and wherefores are discussed and some conclusions reached. This paper is given from a junior doctor's viewpoint but could equally apply to many others.

When I was invited to take part in the conference on medical ethics run by the General Medical Council, I was rather mystified but pleased that I had been chosen: that was until I sat down and thought about what I had done in agreeing to take part.

Medical ethics was, for me, something rather difficult to pin down - it was something that was, rather than something that had to be thought about. Ethics was something that was a part of every doctor rather than a subject that had to be taught, such as anatomy or physics. I knew other people sat down and produced guidelines on medical ethics but when I sat down to put words together I found the going extremely tough.

Sensibly enough I started off by asking for help - I am still wading through the pile of references provided by kind friends. Unfortunately or perhaps fortunately what most of these papers did was to increase my own sense of inadequacy. My so-called working knowledge of medical ethics had very little substance. How could I possibly advise on how to teach a subject I couldn't even define properly!

Anyway having worked my way through a ream of paper and a bottle or two of ink here are a few ideas that might prove helpful.

Most of the questions I asked myself had I felt fairly obvious answers. One or two were however more difficult and I think I have ended up with more questions than answers.

Before I could come to any conclusion on methods of teaching I decided I had to reach a decision on what I was trying to teach. As far as I can remember no one in my student days actually tried to put into simple words what they were talking about when the term 'medical ethics' was used - we were all meant to know! So after

\section{Key words}

Medical ethics; teaching; junior doctors. some hunting I came across the following definition in the Dictionary of Medical Ethics: 'Obligations of a moral nature that govern the practice of medicine'. Even that definition has its problems because the word 'moral' varies in meaning from society to society. Without going into semantics I am going to assume that we belong to a society that has a basic moral code to which we all (or most of us) adhere. How do we learn that code? No one sits down and tells it to us. We absorb our codes of behaviour from those around us, especially in earlier days from our parents. Thus we learn to live within the accepted limits of our own society. As no one consciously teaches us our moral values should anyone try and teach us our medical ethical standards? Do we absorb them from our peers? These are questions that I feel society has already answered for us. With the rapidly advancing medical technology surrounding us society wants to know that its doctors are ready and adequately equipped to deal with any ethical situation that might arise. I feel that we must learn our subject well or fail our patients, and society.

Who shall be taught and who shall teach? The obvious answer lies in the title of this paper. Medical $:-$ students must be given the knowledge on which to base 3 . their decisions, doctors old and new must build on $\delta$ these foundations. As the profession's capabilities increase our awareness of ethical implications must 을 also increase in order to cope with the unforeseen circumstance. Also it must not be forgotten that our para-medical colleagues, as well as our patients, need to be educated. If those we work with and those we care ? for do not understand the codes by which we operate we will be unable to fulfill our roles.

Who shall teach us? The experienced can pass on 0 their valuable knowledge and the inexperienced will ${ }_{0}$ have to learn to listen. Self-teaching is always of value; $\frac{\complement}{\Phi}$ through the medium of discussion interesting ideas can $\stackrel{\odot}{+}$ be explored and appropriate conclusions reached. Our $\square$ more experienced mentors must however remain $\stackrel{P}{\circ}$ flexible and listen to their students 'for out of the $\stackrel{\mathbb{D}}{\mathscr{D}}$ mouths of babes' . . .

The profession, while exchanging knowledge within itself, must not forget the opinions and attitudes that exist in the outside world. Non-medical teachers have음 a valuable part to play. All those outside the profession constitute the consumer and if the consumer is not $\stackrel{0}{7}$ 
satisfied with the end result something is very wrong.

Where should we be taught, the lecture threatre or the tutorial room? How should we be taught, by didactic lecturing or through discussion?

Not having had much formal teaching in medical ethics I did some canvassing of opinion. I asked lots of questions among people I knew and will summarise my conclusions. Most people including myself felt the lecture theatre was appropriate for the teaching of factual material, when little interchange between lecturer and lectured is required. For more abstract subjects, such as medical ethics, the lecture theatre was felt to be inappropriate. Tutorial-type teaching with interplay between tutor and student was felt to be the most productive method available. Medical ethics needs to be discussed and absorbed rather than forced onto a captive audience.

Teaching could also take place within the discussion of aspects of a clinical problem. Each case presentation could include a look at any ethical problems encountered. Relate problems to a specific patient and medical ethics becomes a reality rather than an abstract idea. Everyone I spoke to felt such teaching should be an integral part of the curriculum and not, as in many places, a voluntary sideline for the interested: the uninterested are the very ones we want to reach. Teaching should continue even after graduation - all doctors should regularly discuss with each other the ethical aspects of cases. For only by hearing many points of view will we, as a profession, be able to reach a consensus which in turn will enable us to present a united front if and when we are called upon to defend our own ethical code.

So we come to the 'when' in my list of questions. When does teaching in this subject start and when does it end? The teaching of medical ethics starts on the first day of life and learning. The foundation, on which the medical aspects of ethics are built, is the sound upbringing and the moral values instilled in us by our parents. This groundwork is merely built upon from the day we cross the threshold of our various universities. Medical ethics should be taught from the first day of anatomy until the day we hang up our stethoscopes for ever. As long as we have patient contact we must continue to learn and to develop a sense of medical ethics.

Nothing in this paper should be considered as representing the opinions of the Directorate of the Royal Air Force Medical Services. 